\title{
COMMENTARY
}

\section{Is cortisol the key to the pathogenesis of delirium after coronary artery bypass graft surgery?}

\author{
Jakub Kazmierski* and Iwona Kloszewska \\ See related research by Mu et al., http://ccforum.com/content/14/6/R238
}

\begin{abstract}
Postoperative delirium is a serious complication of cardiac surgery. However, the pathophysiology of this mental syndrome is largely unknown. Recent findings suggest an association between elevated level of cortisol and postoperative delirium. Further studies should investigate the mechanisms responsible for excessive perioperative cortisol secretion.
\end{abstract}

More than 40 years after the first successful coronary artery bypass graft (CABG) surgery was performed, Chinese scientists report the association between high serum cortisol level and delirium, the latter of which is a serious complication of CABG [1]. Prior to 2010, the only study linking higher plasma cortisol and delirium after major surgery was published in 1985 [2]. New findings by $\mathrm{Mu}$ and colleagues [1], published in the previous issue of Critical Care, support the thesis that high serum cortisol level may play a significant role in the pathophysiology of early postoperative delirium.

Available studies revealed that postoperative delirium was associated with significant increases in patient mortality [3]. Furthermore, this neuropsychiatric complication of surgical procedures results in higher risks of sepsis, respiratory failure, sternum instability, and reoperation $[4,5]$. For these reasons, predictors of delirium following cardiac surgery have been intensively investigated, but very recent state-of-the-art studies have brought results that are more consistent (Table 1) $[4,6,7]$. However, the study by $\mathrm{Mu}$ and colleagues aimed to identify the mechanisms underlying factors associated with higher risk of delirium.

The authors hypothesize that the occurrence of postoperative delirium in patients undergoing CABG is

${ }^{*}$ Correspondence: jakub.kazmierski@umed.lodz.pl

Department of Old Age Psychiatry and Psychotic Disorders, Medical University of Lodz, Czechoslowacka 8/10, 92-216 Lodz, Poland associated with stress response and, therefore, with the elevated circulating cortisol level. Indeed, although cortisol is crucial for coping with stress, its excessive and prolonged secretion due to severe, acute stress (that is, major surgery) may contribute to delirium. As mentioned by the authors, high levels of circulating glucocorticoids might have harmful effects on hippocampal activity and thus can cause inattention and cognitive deficits [8]. Moreover, according to experimental studies, hippocampus plays an important role in the regulation of the hypothalamic-pituitary-adrenal (HPA) axis and, as a result, in cortisol secretion. An increased level of cortisol may also be secondary to the dysregulation of the HPA axis in conditions such as depression, dementia, and aging, which are strong predictors of delirium after cardiac surgery (Table 1). Unfortunately, this study did not determine whether an increased level of cortisol is exclusively stress-related or induced by other factors, since screening tests for preoperative depression and cognitive impairment were not performed. The potential confounders like depression, dementia, or impaired executive functioning of the patients were not assessed or excluded from the study and therefore could interfere with the final results of the study. On the other hand, it has to be noticed that none of the available studies regarding higher cortisol level and delirium after major surgery entered psychiatric variables into the analysis.

Hypoxia and perioperative cortical hypoperfusion have been established recently as predictors of postoperative delirium and cognitive deficits [6,9] (Table 1). Moreover, in previous studies, an association between the duration of carotid artery cross-clamping and increased cortisol level was observed, suggesting a positive correlation between cerebral hypoperfusion and excessive cortisol secretion [10]. This interesting issue should be the subject of future investigation. It is worthwhile noticing that preoperative anxiety disorders, like post-traumatic stress disorder, were not associated with postoperative delirium in any of the previous studies [3], although surgeryrelated stress is postulated as contributing to delirium in the article by $\mathrm{Mu}$ and colleagues and in other articles. The putative explanation of this observation is that 
Table 1. Selected independent risk factors of delirium after cardiac surgery according to existing studies [4,6,7]

\begin{tabular}{lll}
\hline Factors related to mental state & Factors related to physical condition & Factors related to anesthetic and surgical procedures \\
\hline Major depression $^{\mathrm{a}}$ & Atrial fibrillation $^{\mathrm{a}}$ & Prolonged intubation \\
Cognitive impairment $^{\mathrm{b}}$ (MMSE score of less than 25) & Anemia $^{\mathrm{a}}$ & Valvular surgery $^{\mathrm{c}}$ \\
Dementia $^{\mathrm{a}}$ & Hypoalbuminemia $^{\mathrm{a}}$ & Extracorporeal circulation $^{\mathrm{c}}$ \\
Disturbed executive functions $^{\mathrm{a}}$ & Peripheral vascular disease $^{\mathrm{a}}$ &
\end{tabular}

Hypoxiab $^{b}$

aPreoperative factors; ${ }^{\text {b }}$ postoperative factors; cless well-documented factors. MMSE, mini-mental state examination.

chronic stress, contrary to acute trauma, is associated with hypocortisolism that is due to hypothalamic supersensitivity to glucocorticoids [11]. Thus, the deleterious effect of increased cortisol plasma concentration is avoided. Recently, Plaschke and colleagues [12] reported that, besides cortisol, an increased level of interleukin-6 is associated with delirium among individuals after openheart surgery. However, that study was conducted in a smaller $(\mathrm{n}=114)$ and more heterogeneous population (patients referred for different types of cardiac surgery). Several studies suggest the association between delirium and the apolipoprotein E4 allele in older patients, but the results are inconsistent and depend on the methodology used by the researchers [13]. Moreover, variations in the $S L C 6 A 3$ gene and possibly the DRD2 gene were found to provide protection from delirium in a mixed population of surgery and non-surgery patients [14].

The baseline concentration of plasma cortisol was not measured in the study by $\mathrm{Mu}$ and colleagues or in the two other studies investigating the association between high cortisol level and postoperative delirium [12,15]. This limitation prevented $\mathrm{Mu}$ and colleagues from drawing a more detailed conclusion regarding the causative role of cortisol in delirium development. Still, it should be noted that their study was well designed and was conducted in a large and homogenous population. The novel and reasonable endeavor was the use of Richmond Agitation Sedation Scale to detect deeply sedated or unarousable subjects before the final assessment of delirium was performed.

An elevated level of cortisol seems to play an important role in the pathophysiology of delirium after CABG. However, the mechanisms responsible for excessive perioperative cortisol secretion are unclear. Future studies should investigate these mechanisms and the role of factors such as cerebral hypoperfusion, gene polymorphism, and cytokines.

\section{Abbreviations}

CABG, coronary artery bypass graft; HPA, hypothalamic-pituitary-adrenal.

\section{Competing interests}

The authors declare that they have no competing interests.

Published: 13 January 2011

References

1. Mu D-L, Wang D-X, Li L-H, Shan G-J, Li J, Yu Q-J, Shi C-X: High serum cortisol level is associated with increased risk of delirium after coronary artery bypass graft surgery: a prospective cohort study. Crit Care 2010, 14:R238.

2. Mclntosh TK, Bush HL, Yeston NS, Grasberger R, Palter M, Aun F, Egdahl RH: Beta-endorphin, cortisol and postoperative delirium: a preliminary report. Psychoneuroendocrinology 1985, 10:303-313.

3. Detroyer E, Dobbels F, Verfaillie E, Meyfroidt G, Sergeant P, Milisen K: Is preoperative anxiety and depression associated with onset of delirium after cardiac surgery in older patients? A prospective cohort study. J Am Geriatr Soc 2008, 56:2278-2284.

4. Bucerius J, Gummert JF, Borger MA, Walther T, Doll N, FalkV, Schmitt DV, Mohr FW: Predictors of delirium after cardiac surgery delirium: effect of beatingheart (off-pump) surgery. J Thorac Cardiovasc Surg 2004, 127:57-64.

5. Martin BJ, Buth KJ, Arora RC, Baskett RJ: Delirium as a predictor of sepsis in post-coronary artery bypass grafting patients: a retrospective cohort study. Crit Care 2010, 14:R171.

6. Kazmierski J, Kowman M, Banach M, Fendler W, Okonski P, Banys A, Jaszewski R, Rysz J, Mikhailidis DP, Sobow T, Kloszewska I; IPDACS Study: Incidence and predictors of delirium after cardiac surgery: results from The IPDACS Study. J Psychosom Res 2010, 69:179-185.

7. Rudolph JL, Jones RN, Levkoff SE, Rockett C, Inouye SK, Sellke FW, Khuri SF, Lipsitz LA, Ramlawi B, Levitsky S, Marcantonio ER: Derivation and validation of a preoperative prediction rule for delirium after cardiac surgery. Circulation 2009, 20:229-236.

8. Lupien SJ, Gillin CJ, Hauger RL: Working memory is more sensitive than declarative memory to the acute effects of corticosteroids: a doseresponse study in humans. Behav Neurosci 1999, 113:420-430.

9. Chida K, Ogasawara K, Aso K, Suga Y, Kobayashi M, Yoshida K, Terasaki K, Tsushina E, Ogawa A: Postcarotid endarterectomy improvement in cognition is associated with resolution of crossed cerebellar hypoperfusion and increase in 1231-iomazenil uptake in the cerebral cortex: a SPECT study. Cerebrovasc Dis 2010, 29:343-351.

10. Marrocco-Trischitta MM, Tiezzi A, Svampa MG, Bandiera G, Camilli S, Stillo F, Petasecca P, Sampogna F, Abeni D, Guerrini P: Perioperative stress response to carotid endarterectomy: the impact of anesthetic modality. J Vasc Surg 2004, 39:1295-1304.

11. Raison $\mathrm{CL}$, Miller $\mathrm{AH}$ : When not enough is too much: the role of insufficient glucocorticoid signaling in the pathophysiology of stress-related disorders. Am J Psychiatry 2003, 160:1554-1565.

12. Plaschke K, Fichtenkamm P, Schramm C, Hauth S, Martin E, Verch M, Karck M, Kopitz J: Early postoperative delirium after open-heart cardiac surgery is associated with decreased bispectral EEG and increased cortisol and interleukin-6. Intensive Care Med 2010, 36:2081-2089.

13. van Munster BC, Korevaar JC, Zwinderman AH, Leeflang MM, de Rooij SE: The association between delirium and the apolipoprotein E epsilon 4 allele: new study results and a meta-analysis. Am J Geriatr Psychiatry 2009, 17:856-862.

14. van Munster BC, de Rooij SE, Yazdanpanah M, Tienari PJ, Pitkälä KH, Osse RJ, Adamis D, Smit O, van der Steen MS, van Houten M, Rahkonen T, Sulkava R, Laurila JV, Strandberg TE, Tulen JH, Zwang L, MacDonald AJ, Treloar A, Sijbrands EJ, Zwinderman AH, Korevaar JC: The association of the dopamine transporter gene and the dopamine receptor 2 gene with delirium, a meta-analysis. Am J Med Genet B Neuropsychiatr Genet 2010, 5:648-655.

15. Shi CM, Wang DX, Chen KS, Gu XE: Incidence and risk factors of delirium in critically ill patients after non-cardiac surgery. Chin Med J (Engl) 2010, 20:993-999.

doi:10.1186/cc9372

Cite this article as: Kazmierski J, Kloszewska I: Is cortisol the key to the pathogenesis of delirium after coronary artery bypass graft surgery? Critical Care 2011, 15:102. 